\title{
Influence of Bloodmeal Source on Reproductive Output of the Potential West Nile Vector, Culex theileri (Diptera: Culicidae)
}

\author{
BERNA DEMIRCI, ${ }^{1,2}$ ESRA DURMAZ, ${ }^{3}$ AND BULENT ALTEN ${ }^{4}$
}

\begin{abstract}
J. Med. Entomol. 51(6): 1312-1316 (2014); DOI: http://dx.doi.org/10.1603/ME13197
ABSTRACT Culex theileri Theobald (Diptera: Culicidae) has a wide Afrotropical, southern Palaearctic, northern Oriental, and European distribution. It is mainly considered as a mammophilic mosquito and also feeds on birds and serves as a vector for various zoonotic diseases including West Nile virus. Despite its broad distribution and evidence indicating that $C x$. theileri is a competent vector of human and domestic animal pathogens, basic biological and ecological features of this species have not been well investigated. We evaluated the impact of bloodmeal source (human, chicken, cow, and a double bloodmeal such as human and cow or chicken and cow and mixed bloodmeals [cow, chicken, and human] via artificial feeding) on fecundity, hatching rates, developmental times, and viability from egg to adult for laboratory colonized $C x$. theileri. Fecundity in mosquitoes that took a chicken bloodmeal, a double bloodmeal and mixed bloodmeals was significantly higher than in females fed on a single cow or single human blood. This is the first study about the bloodmeal sources effect on laboratory-reared $C x$. theileri populations and these findings contribute to our understanding of the impact of bloodmeal source on reproduction in $C x$. theileri. As it is known that $C x$. theileri is a vector for West Nile virus, the potential impacts of bloodmeal source on virus transmission are discussed.
\end{abstract}

KEY WORDS Culex theileri, West Nile virus, fecundity, bloodmeal source, multiple feeding

Anautogenous female mosquitoes require the protein from blood to develop eggs (Clements 1992). According to Briegel (1990), blood-feeding has a crucial role in a female mosquito's reproductive success, as most species require bloodmeal to obtain amino acids from erythrocytes and plasma protein digestion to synthesize yolk proteins for egg production. Laboratory studies have shown that host blood source affects the gonotrophic cycle (Mather and DeFoliart 1983). The size of a bloodmeal from different sources varies and results in significant differences in number of eggs laid per female (Taylor and Hurd 2001, Roitberg and Gordon, 2005). These variations have been attributed to differences in protein and amino acid content of the bloodmeals (Prasad 1987). Blood feeding on different host species (double meal) during a single gonotrophic cycle is a common mosquito behavior (Edman and Downe 1964, Xue and Edman 1991, Xue et al. 1995). Because multiple bloodmeals are an important contribution to mosquito fitness, and in some cases are essential for reproduction, in female Anopheline species, multiple bloodmeals are important components of the reproductive strategy (Briegel and Horler 1993). At emergence, a proportion of mosquitoes, es-

\footnotetext{
${ }^{1}$ Department of Biology, Faculty of Science, Kafkas University, 36100 Kars, Turkey.

${ }^{2}$ Corresponding author, e-mail: demirciberna80@gmail.com.

${ }^{3}$ Department of Ecology and Evolution, University of Lausanne, UNIL Sorge, Le Biophore, CH-1015 Lausanne, Switzerland.

${ }^{4}$ Department of Biology, Faculty of Science, Hacettepe University, 06800 Beytepe Ankara, Turkey.
}

pecially small females, lack metabolic energy reserves to initiate previtellogenesis, and hence need blood as a nutritional source for essential metabolic processes (Scott and Takken 2012). Also, because a double bloodmeal increases the number of host contact events by a single female, such behavior in the mosquito populations can affect their vectorial capacity (Scott et al. 1993).

Culex theileri Theobald has a wide Afrotropical, southern Palearctic, northern Oriental, and European distribution. It is mainly considered a mammophilic mosquito that also feeds on birds (Alcaide et al. 2009, Munoz et al. 2012, Osório et al. 2012). Cx. theileri is naturally infected with West Nile virus, Rift Valley fever virus, and Sindbis virus in South Africa (Jupp et al. 1966, Mclntosh et al. 1967, Harbach 1988). In Iran, females were found to be naturally infected with third-stage larvae of Dirofilaria immitis (Leidy) (Azari-Hamidianet al. 2009). Field and laboratory studies verified that the species is a natural vector of $D$. immitis in Maderia Island, Portugal (Santa-Ana et al. 2006). In Iraq, Cx. theileri has been implicated in West Nile virus transmission (Abul-Hab 1967).

In Europe, it has been reported from Portugal, Spain, France, Italy, Yugoslavia, Greece, Hungary, Bulgaria, and Ukraine (Becker et al. 2003), and it is one of the most common mosquito species in Turkey. The larvae occur in spring in flooded meadows, stagnant or slowly moving streams, ditches, rock pools, drains, swamps, rice fields, and in artificial containers. Larvae can also be found in highly polluted water (Aitken 
1954, Ramos et al. 1977) and can tolerate a range of salinity, from fresh or slightly saline water from 2 to $16.6 \mathrm{~g} \mathrm{NaCl} /$ liter and $\mathrm{pH}$ 5.5-9.5 (Ramos et al. 1977). $C x$. theileri has a very wide distribution in permanent breeding sites in the eastern part of Turkey and it prefers natural habitats in rural areas with large larval breeding sites (Simsek 2004, Aldemir et al. 2010).

Despite its broad distribution and evidence indicating that $C x$. theileri is a competent vector of human and domestic animal pathogens, the basic biological and ecological aspects of this species have not been well investigated. This study was carried out to elucidate the influence of different bloodmeal sources on fecundity, hatching rates, developmental times, and viability from egg to adult for laboratory colonized $C x$. theileri species. This is the first study about the influence of bloodmeal sources on reproductive success of $C x$. theileri and this information will improve our understanding of how bloodmeal source affects survivorship and fecundity in a mosquito population. It will also allow more precise assessments about the transmission risk of mosquito-borne disease agents to humans and animals.

\section{Materials and Methods}

Establishment of Populations. Mosquito trapping was conducted in northeastern Turkey. Sampling included sites located along the Aras River and Kars Plateau. The study area is on the way of one of the world's biggest bird migration routes and every year millions of birds migrate from Russia and Caucasus to Middle East and Africa using the river deltas, flood plains, or lakes in this region as resting and mating areas. In August 2011, we established a colony of $C x$. theileri with blood-fed adults from this area. $C x$. theileri adults were collected from cattle and sheep barns using mouth aspirators and New Jersey light traps containing 40-Watt light bulbs. On each trapping night, five to seven light traps were placed in each of the sampling localities. New Jersey light traps were placed $1.5 \mathrm{~m}$ above ground, and they were operated from 1800 to 0600 hours. Field-collected live adults (blood-fed or gravid) were cooled to $4^{\circ} \mathrm{C}$ and then transferred to the laboratory. The identification of the species were done by following the keys and descriptions of Schaffner et al. (2001).

$C x$. theileri populations reared in the laboratory conditions with a temperature of $27 \pm 2{ }^{\circ} \mathrm{C}, 70 \pm 5 \%$ relative humidity, and a photoperiod of 12:12 (L:D) h. Dawn and dusk phases were simulated with automatically dimmed fluorescent bulbs activated between 0600-0700 and 1800-1900 hours. Fed and gravid adults were kept in separate cloth cages and were fed with $10 \%$ sucrose solution. Larvae were reared in polyethylene containers ( 20 by $40 \mathrm{~cm}$ ) filled with water of $5 \mathrm{~cm}$ depth (Briegel et al. 2003). For colony maintenance, females were blood-fed weekly on rabbits.

Mosquito Feeding. For bloodmeal sources, chicken, human, and cow were used to conduct single, double, and multiple blood-feeding experiments. For single blood feeding each type of blood (Human "hu," cow "cw," and chicken "chi") used separately. For double feeding, the binary combinations of each blood type (human + chicken "hu + chi", human + cow "hu + cw," chicken + cow "chi + cw") were used. For mixed feeding, we mixed all types of blood (human + cow + chicken "hu $+\mathrm{cw}+$ chi") and all these experiments were performed three times.

Six- to ten-day-old $C x$. theileri females were starved $24 \mathrm{~h}$ before experiments. Bloodmeals were offered artificially through a membrane (lamb intestine). Blood was warmed to $37^{\circ} \mathrm{C}$ by circulating water bath through a glass-jacketed feeder. The feeding membrane placed on the top of the mosquito cages, allowing females to feed through the mesh. In a single blood feeding, the membrane was filled with $6 \mathrm{ml}$ of chicken, cow, or human blood. In double or multiple blood feedings, the membrane was filled with equal volume of each blood type. After each blood-feeding experiment, successfully fed mosquitoes were aspirated from the cages and cultured individually in 25-ml glass vials filled with $5 \mathrm{ml}$ of distilled water at the bottom as oviposition site.

After oviposition, the eggs were transferred to polyethylene containers ( 20 by $40 \mathrm{~cm}$ ) filled with water $(5$ $\mathrm{cm}$ in depth) at a density of 100 larvae per container. Larvae were fed twice daily with Tetramin fish food. Each day data were collected on number of oviposited eggs for each female. Also, for each blood treatment, 15 females were followed to determine the development of the eggs, egg hatching, preadult period, and pupation and maturation ratio.

Determination of Reproductive Output and Statistical Analysis. Oviposition rate was determined as the proportion of engorged mosquitoes that eventually laid eggs. Fecundity was determined as the total number of eggs laid per mosquito. Egg hatching rate was estimated as the proportion of eggs hatched per mosquito. Preadult period was defined as the length of time that an egg requires to emerge as an adult. Pupation rate was defined as the proportion of first-instar larvae that developed to the pupal stage. Maturation rate was defined as the proportion of eggs that became adults.

Statistical analyses for data collected were carried out using Statistica software version 7.1. One-way analysis of variance and Duncan's multiple comparisons were performed to calculate the significance level.

\section{Results}

Table 1 shows the results from blood-feeding treatments. Oviposition rate was varied across the bloodmeal sources and most favored by chicken bloodmeal and chicken + cow double bloodmeal $($ mean $=79.06$ and $75.55 \%$, respectively). However, the groups of mosquitoes fed with cow bloodmeal and chicken + human double bloodmeal had the least number of individuals that oviposited (mean $=41.37$ and $42.1 \%$, respectively). Fecundity varied significantly across bloodmeal sources (Table 1). It was significantly higher in mosquitoes fed on double and multiple hosts 
Table 1. Results from the blood-feeding experiments

\begin{tabular}{|c|c|c|c|c|c|c|c|}
\hline & Chicken (Chi) & Cow $(\mathrm{Cw})$ & Human $(\mathrm{Hu})$ & $\mathrm{Chi}+\mathrm{Cw}$ & $\mathrm{Chi}+\mathrm{Hu}$ & $\mathrm{Cw}+\mathrm{Hu}$ & $\mathrm{Chi}+\mathrm{Cw}+\mathrm{Hu}$ \\
\hline No. the blood-fed females & 43 & 58 & 26 & 48 & 57 & 45 & 49 \\
\hline Total egg no. & 5,872 & 3,069 & 2,017 & 5,653 & 4,026 & 4,895 & 5,366 \\
\hline No. hatching eggs & 5,458 & 2,622 & 1,827 & 4,984 & 3,505 & 4,236 & 4,761 \\
\hline Oviposition ratio (\%) & 79.06 & 41.37 & 65.38 & 75.55 & 421 & 68.88 & 61.22 \\
\hline Fecundity & $172.27 \pm 44.35^{\mathrm{a}}$ & $127.87 \pm 36.73^{\mathrm{b}}$ & $118.64 \pm 40.56^{\mathrm{bc}}$ & $167.84 \pm 31.11^{\mathrm{ad}}$ & $164.95 \pm 64.78^{\mathrm{ad}}$ & $153.16 \pm 46.83^{\mathrm{abd}}$ & $182.2 \pm 31.90^{\mathrm{ad}}$ \\
\hline Egg hatching ratio (\%) & $93.00 \pm 3.92^{\mathrm{a}}$ & $85.00 \pm 4.87^{\mathrm{ad}}$ & $91.00 \pm 4.86^{\mathrm{a}}$ & $88.00 \pm 5.39^{\mathrm{a}}$ & $87.00 \pm 7.66^{\mathrm{bc}}$ & $87.00 \pm 6.23^{\mathrm{bd}}$ & $89.00 \pm 7.90^{\mathrm{b}}$ \\
\hline Pre-adult period (day) & $18.90 \pm 3.66^{\mathrm{a}}$ & $23.32 \pm 8.85^{\mathrm{b}}$ & $18.16 \pm 3.65^{\mathrm{bc}}$ & $19.03 \pm 3.75^{\mathrm{bc}}$ & $20.37 \pm 4.07^{\mathrm{b}}$ & $18.85 \pm 4.53^{\mathrm{bc}}$ & $20.9 \pm 4.27^{\mathrm{b}}$ \\
\hline Pupation ratio $(\%)$ & $2.04 \pm 1.71^{\mathrm{a}}$ & $0.96 \pm 0.82^{\mathrm{b}}$ & $0.81 \pm 0.61^{\mathrm{b}}$ & $3.15 \pm 1.46^{\mathrm{a}}$ & $1.28 \pm 0.95^{\mathrm{bc}}$ & $2.65 \pm 2.06^{\mathrm{a}}$ & $1.83 \pm 1.44^{\mathrm{a}}$ \\
\hline Maturation ratio (\%) & $1.67 \pm 1.57^{\mathrm{a}}$ & $0.69 \pm 0.65^{\mathrm{b}}$ & $0.63 \pm 0.54^{\mathrm{b}}$ & $2.64 \pm 1.35^{\mathrm{a}}$ & $1.05 \pm 0.74^{\mathrm{b}}$ & $2.05 \pm 1.5 \mathrm{l}^{\mathrm{a}}$ & $1.36 \pm 1.04^{\mathrm{a}}$ \\
\hline
\end{tabular}

Summarized results from three replicates are shown for each treatment. Values followed by same superscript letter in a row are not significantly different at $P=0.05$ level of significance.

compared with be fed on single hosts accept chicken (Table 1). Egg hatching rate in the mosquitoes was generally high (between 85 and 93\%), where it was differed significantly across some bloodmeal sources (Table 1 ). Preadult period was differed significantly across some bloodmeal sources (Table 1), where it was significantly longest in mosquitoes fed on cow bloodmeal $(23.32 \pm 8.85 \mathrm{~d})$ and chicken + human double bloodmeal $(20.37 \pm 4.07 \mathrm{~d})$. Pupation rate was differed significantly across some bloodmeal sources and was higher in mosquitoes fed on chicken + cow double bloodmeal and human + cow double bloodmeal (mean $=3.15$ and $2.65 \%$, respectively). Maturation rate was significantly lower in mosquitoes fed on cow, human, and chicken + human bloodmeal (Table 1).

\section{Discussion}

Our results show that a bloodmeal source affects reproductive output in laboratory-reared $C x$. theileri populations. These findings agree with previous reports that show a strong positive correlation between a bloodmeal source and mosquito reproductive output especially fecundity (Clements 1992, Islam and Ferdousi 1999, Richards et al. 2010, Oleyemi et al. 2011). Fecundity, pupation rate, and maturation ratio in mosquitoes that took a single chicken bloodmeal or a double or mixed bloodmeals were higher than in females fed on a single cow or single human blood.

According to Briegel and Horler (1993), multiple bloodmeals improve reproductive success and may be reproductive enhancement strategy in Anopheles spp. Our results are in agreement with Briegel and Horler (1993). Similar findings about the positive correlation between multiple bloodmeals and reproductive success reported in Aedes albopictus (Skuse) by Xue et al. 2009. Multiple feeding not only increases the mosquito fecundity but also increases the risk of pathogen transmission because of multiple host contacts by an infected mosquito during a single gonotrophic cycle.

Fecundity was significantly higher in $C x$. theileri mosquitoes fed on single chicken than in mosquitoes fed on single cow or human. A similar influence of chicken blood on fecundity and fertility rates of Culex pipiens quinquefasciatus Say was reported by Richards et al. 2010. In addition, Culex tarsalis Coquillet showed higher fecundity when fed on chickens compared with guinea pigs or snakes (Downe and Archer 1975).
Chicken blood contains nucleated blood cells, while mammalian blood contains anucleated cells, which has been hypothesized to influence fecundity that nucleated cells contain more nutrition (Bennett 1970, Downe and Archer 1975). Also, these results may be derived from the difference of the energetic costs of digestion. These costs would include secretion of enzymes, the metabolism of the blood components, the excretion of the toxic by-products, and the heat increment of feeding (Clements 1992). Even if the base nutritional value of blood from different host sources is similar, the energetic costs of digesting it might not be. Blood digestion requires a substantial expenditure of energy; the metabolic rate of the mosquito $C x$. tarsalis, for example, doubles when it is consuming blood in comparison with when it is consuming sugar water (Gray and Bradley 2003). The time required to digest blood can also vary among host species; for example, $C x$. tarsalis digests the blood of its preferred chicken hosts at a faster rate than it digests blood from rodents (Downe and Archer, 1975). Thus, these findings maybe because of different rates of digestion and nutrition for different blood sources.

However, the energy cost of digestion is not the only parameter that determines energetic efficiency of foraging and ultimately of host selection by a parasite. Other expenditures associated with foraging activities include searching for the host, feeding site selection for piercing the skin of the host and obtaining a bloodmeal, time required for a bloodmeal, and surviving antiparasitic grooming effort of a host. For example, Bennet, 1970 showed that Aedes aegypti (L.) produced more eggs when fed on avian than fed on mammalian even though it primarily is a human feeder. Even though these artificial bloodmeal delivery systems are an important tool for laboratory studies where the use of animals is not possible, these studies should consider that the bloodmeal source, whether delivered via animal or artificial method, may affect physiological processes leading to reproduction in laboratory colonized mosquitoes and could influence results. In addition, these laboratory studies generally did not include all host species that the target mosquito fed upon in nature and/ or only looked at one component of mosquito fitness, which may not be indicative of their total lifetime reproductive success.

Overall, this is the first experimental study about the influence of bloodmeal sources on reproductive out- 
put of the potential West Nile vector $C x$. theileri. These results should be considered of interest in transmission of West Nile virus by $C x$. theileri. West Nile virus is a zoonotic pathogen that is primarily transmitted between birds and mosquitoes, particularly Culex species, and is also transmitted to mammals, including horses and humans (Kramer and Bernard 2001, Campell et al. 2002). In Europe, West Nile virus circulation exhibits rural and urban cycles of transmission. Because avian population distribution has a critical influence in West Nile virus transmission and rural foci of West Nile infections are mainly situated in wetland ecosystems (river deltas or flood plains), wild and domestic birds in these areas are the main reservoirs that may amplify the virus spread by migratory birds (Malkinson and Banet 2002).

The sampling area included sites located along the Aras River and Kars Plateau. This area is on the way of one of the world's biggest bird migration routes and every year millions of birds migrate from Russia and Caucasus to Middle East and Africa using the river deltas, flood plains, or lakes in this region as resting and mating areas. When we consider the higher reproductive success of $C x$. theileri that fed on chicken blood and multiple hosts, we suggest that this mosquito may play an important role in amplifying West Nile virus in this bird migration region. As $C x$. theileri is a vector organism for West Nile virus and co-occur with potential host species in the same region, the importance of this bird migration area is critical. Therefore, the vectorial capacity of $C x$. theileri and potential risks of spreading West Nile virus arising from bird migration should be considered and monitored more carefully in the future in the study area.

\section{Acknowledgments}

This research was conducted according to principles stated in the "Guide for the Care and Use of Laboratory Animals." This study is a part of B.D. Ph.D. thesis.

\section{References Cited}

Abul-Hab, J. 1967. Larvae of culicine mosquitoes in North Iraq. Bull. Entomol. Res. 57: 279-284.

Aitken, T.H.G. 1954. The Culicidae of Sardinia and Corsica (Diptera). Bull. Entomol. Res. 45: 437-494.

Alcaide, M., C. Rico, S. Ruiz, R. Soriguer, J. Munõz, and J. Figuerola. 2009. Disentangling vector-borne transmission networks: a universal DNA barcoding method to identify vertebrate hosts from arthropod bloodmeals. PLoS One 4: e7092.

Aldemir, A., H. Bedir, B. Demirci, and B. Alten. 2010. Biting activity of mosquito species (Diptera: Culicidae) in the Turkey-Armenia border area, Ararat Valley, Turkey. J. Med. Entomol. 47: 22-27.

Azari-Hamidian, S., M. R. Yaghoobi-Ershadi, E. Javadian, M. R. Abai, I. Mobedi, Y. M. Linton, and R. E. Harbach. 2009. Distribution and ecology of mosquitoes in a focus of dirofilariasis in northwestern Iran, with the first finding of filarial larvae in naturally infected local mosquitoes. Med. Vet. Entomol. 23: 111-121.
Becker, N., D. Petrić, M. Zgomba, C. Boase, C. Dahl, J. Lane, and A. Kaiser. 2003. Mosquitoes and their control. Kluwer Academic/Plenum Publishers, New York.

Bennet, G. F. 1970. The influence of the blood meal type on the fecundity of Aedes aegypti (Stegomyia) L. (Diptera: Culicidae). Can. J. Zool. 48: 539-543.

Briegel, H. 1990. Metabolic relationship between female body size, reserves, and fecundity of Aedes aegypti. J. Insect. Physiol. 36: 165-172.

Briegel, H., and E. Horler. 1993. Multiple blood meals as a reproductive strategy in Anopheles (Diptera: Culicidae). J. Med Entomol. 30: 975-985.

Briegel, H., T. Gut, and A. O. Lea. 2003. Sequential deposition of yolk components during oogenesis in an insect, Aedesaegypti (Diptera: Culicidae). J. Insect Physiol. 49: 249-260.

Clements, A. N. 1992. Development, nutrition and reproduction. I. In The biology of mosquitoes. Chapman \& Hall, London, UK.

Downe, A.E.R., and J. A. Archer. 1975. Effects of different bloodmeal sources on digestion and egg production in Culex tarsalis Coq (Diptera:Culicidae). J. Med. Entomol. 12: 431-437.

Edman, J. D., and A.E.R. Downe. 1964. Host-blood sources and multiplefeeding habits of mosquitoes in Kansas. Mosq. News 24: 155-160.

Gray, E. M., and T. J. Bradley. 2003. Metabolic rate in female Culex tarsalis (Diptera: Culicidae): age, size, activity, and feeding effects. J. Med. Entomol. 40: 903-911.

Harbach, R. E. 1988. The mosquitoes of the subgenus Culex in southwestern Asia and Egypt (Diptera: Culicidae). Contrib. Am. Entomol. Inst. 24: 1-240.

Islam, M. S., and Z. Ferdousi. 1999. Effect of blood-meals from different vertebrates on the reproductive attributes in the mosquito Culexquinquefasciatussay (Diptera: $\mathrm{Cu}-$ licidae). J. Asiat. Soc. Bangladesh Sci. 25: 315-325.

Jupp, P. G., B. M. Mclntosh, and R. G. Brown. 1966. Laboratory transmission experiments with West Nile and Sindbis viruses and Culex (Culex) theileri Theobald. S. Afr. J. Med. Sci. 31: 95-97.

Kramer, L. D., and K. A. Bernard. 2001. West Nile virus in the western hemisphere. Curr. Opin. Infect. Dis. 14: 519525.

Malkinson, M., and C. Banet. 2002. The role of birds in the ecology of West Nile Virus in Europe and Africa. Curr. Top. Microbiol. Immunol. 267: 309-322.

Marshall, A. G. 1981. The ecology of ectoparasitic insects. Academic, London, United Kingdom.

Mather, T. N., and G. R. DeFoliart. 1983. Effect of host blood source on the gonotrophiccycle of Aedes triseriatus. Am. J. Trop. Med. Hyg. 32: 189-193.

Mclntosh, B. M., P. G. Jupp, D. B. Dickinson, G. M. McGillivary, and J. Sweetnam. 1967. Ecological studies on Sindbis and West Nile viruses in South Africa. I. Viral activity as revealed by infection of mosquitoes and sentinel fowls. S. Afr. J. Med. Sci. 32: 1-14.

Munoz, J., S. Ruiz, R. C. Soriguer, M. Alcaide, D. S. Viana, D. Roiz, A. Vazquez, and J. Figuerola. 2012. Feeding patterns of potential West Nile virus transmission vectors in Southwest Spain. PLoS One 7: e39549.

Oleyemi, I. K., A. T. Ande, G. Danlami, and U. Abdullahi. 2011. Influence of blood meal type on reproductive performance of the malaria vector, Anopheles gambiaes. s (Diptera: Culicidae). J. Entomol. 8: 459-467.

Osório, H. C., L. Zé-Zé, and J. M. Alves. 2012. Host-feeding patterns of Culex pipiens and other potential mosquito vectors (Diptera: Culicidae) of West Nile virus (Flavi- 
viridae) collected in Portugal. J. Med. Entomol. 49: 717721.

Prasad, R. S. 1987. Nutrition and reproduction in haematophagous arthropods. Proc. Anim. Sci. 96: 253-273.

Ramos, H. C., H. Ribeiro, C. A. Pires, and R. A. Capela. 1977. Research on the mosquitoes of Portugal (Diptera, Culicidae). II-The mosquitoes of the Algarve. Ann. Inst. Hyg. Med. Trop., 5: 237-256.

Richards, S. L., S. L. Anderson, and S. A Yost. 2010. Effects of blood meal source on the reproduction of Culex pipiens quinquefasciatus (Diptera: Culicidae). J. Vector Ecol. 37: $1-7$.

Roitberg, B. D., and I. Gordon. 2005. Does another blood meal-fecundity curve, curve? J. Vector Ecol. 30: 83- 86.

Santa-Ana, M., M. Khadem, and R. Capela. 2006. Naturalinfection of Culex theileri (Diptera: Culicidae) with Dirofilaria immitis (Nematoda: Filarioidea) on Madeira Island, Portugal. J. Med. Entomol. 43: 104-106.

Schaffner, F., G. Angel, B. Geoffroy, J. P. Hervy, A. Rhaiem, and J. Brunhes. 2001. Les moustiquesdÕEurope (The mosquitoes of Europe), CD-ROM. Institut deRecherche pour Development/EID Mediterrane' e. Montpellier, France.

Scott, T. W., and W. Takken. 2012. Feeding strategies of anhropophilic mosquitoes result in increased risk of pathogen transmission. Trends Parazitoloji. 28(3): 114121.
Scott, T. W., G. G. Lorenz, P. H. Amerasinghe, P. Reiter, J. D. Edman. 1993. Detection of multiple blood feeding in Aedes aegypti (Diptera: Culicidae) during a single gonotrophic cycle using a histologic technique. J. Med Entomol. 30: 94-99.

Simsek, F. M. 2004. Seasonal larval and adult population dynamics and breeding habitat diversity of Culex theileri Theobald, 1903 (Diptera: Culicidae) in the Golbasi District, Ankara, Turkey. Turk J. Zool. 28: 337-344.

Taylor, P. J., and H. Hurd. 2001. The influence of host haematocrit on the blood feeding success of Anopheles stephensi: implications for enhanced malaria transmission. Parasitology 122: 491-496.

Xue, R. D., and J. D. Edman. 1991. Multiple blood feeding of mosquitoes and influencing factors, a review, pp. 137155. In Y. -X. Yu (ed.), Contributions on blood-sucking dipterous insects, vol. 3. Shanghai Science \& Technology, Shanghai, People's Republic of China.

Xue, R. D., J. D. Edman, and T. W. Scott. 1995. Age and body size effects on blood meal size and multiple blood feeding by Aedes aegypti (Diptera: Culicidae). J. Med Entomol. 32: 471-474.

Xue, R. D., D. R. Barnard, and A. Ali. 2009. Influence of multiple blood meals on gonotrophic dissociation and Fecundity in Aedes albopictus. J. Am. Mos. Control Assoc. 25: 504-507.

Received 1 October 2013; accepted 14 August 2014. 